Article

\title{
Mitigation of Condensate Banking Using Thermochemical Treatment: Experimental and Analytical Study
}

\author{
Amjed M. Hassan ${ }^{1}$ (D), Mohamed A. Mahmoud ${ }^{1, *}$, Abdulaziz A. Al-Majed 1,*, \\ Ayman R. Al-Nakhli ${ }^{2}$, Mohammed A. Bataweel ${ }^{2}$ and Salaheldin Elkatatny ${ }^{1}$ \\ 1 College of Petroleum Engineering and Geosciences, King Fahd University of Petroleum \& Minerals, \\ Dhahran 31261, Saudi Arabia; amjed.moh06@gmail.com (A.M.H.); elkatatny@kfupm.edu.sa (S.E.) \\ 2 Saudi Aramco, Dhahran 31311, Saudi Arabia; nakhliar@gmail.com (A.R.A.-N.); \\ batawema@yahoo.com (M.A.B.) \\ * Correspondence: aamajed@kfupm.edu.sa (M.A.M.); mmahmoud@kfupm.edu.sa (A.A.A.-M.)
}

Received: 10 December 2018; Accepted: 26 February 2019; Published: 28 February 2019

\begin{abstract}
Condensate banking is a common problem in tight gas reservoirs because it diminishes the gas relative permeability and reduces the gas production rate significantly. $\mathrm{CO}_{2}$ injection is a common and very effective solution to mitigate the condensate damage around the borehole in tight gas reservoirs. The problem with $\mathrm{CO}_{2}$ injection is that it is a temporary solution and has to be repeated frequently in the field in addition to the supply limitations of $\mathrm{CO}_{2}$ in some areas. In addition, the infrastructure required at the surface to handle $\mathrm{CO}_{2}$ injection makes it expensive to apply $\mathrm{CO}_{2}$ injection for condensate removal. In this paper, a new permanent technique is introduced to remove the condensate by using a thermochemical technique. Two chemicals will be used to generate in situ $\mathrm{CO}_{2}$, nitrogen, steam, heat, and pressure. The reaction of the two chemicals downhole can be triggered either by the reservoir temperature or a chemical activator. Two chemicals will start reacting and produce all the mentioned reaction products after $24 \mathrm{~h}$ of mixing and injection. In addition, the reaction can be triggered by a chemical activator and this will shorten the time of reaction. Coreflooding experiments were carried out using actual condensate samples from one of the gas fields. Tight sandstone cores of $0.9 \mathrm{mD}$ permeability were used. The results of this study showed that the thermochemical reaction products removed the condensate and reduced its viscosity due to the high temperature and the generated gases. The novelty in this paper is the creation of micro-fractures in the tight rock sample due to the in-situ generation of heat and pressure. These micro-fractures reduced the capillary forces that hold the condensate and enhanced the rock relative permeability. The creation of micro-fractures and in turn the reduction of the capillary forces can be considered as permanent condensate removal.
\end{abstract}

Keywords: tight reservoirs; condensate banking; thermochemical treatment; new method; permanent technique

\section{Introduction}

Gas reservoirs are playing a significant rule in the energy supply due to its abundance, low price, and low emission of greenhouse gases compared to crude oil [1]. Natural gas reservoirs are classified into wet gas, dry gas, or retrograde gas condensate; based on the reservoir conditions and hydrocarbon composition. During hydrocarbon production, the reservoir pressure declines due to depletion, especially in the near-wellbore region. Therefore, the gas starts to condensate and generate a liquid bank around the wellbore, this phenomenon is defined as condensate banking. The condensate 
accumulation causes significant reduction in the gas relative permeability and reservoir deliverability. The impact of condensate banking on the gas relative permeability $\left(\mathrm{K}_{\mathrm{rg}}\right)$ is shown in Figure 1 . As the distance from the borehole increases, the condensate saturation (green curve) decreases, and then, the relative permeability to gas (red curve) increases. Usually, the saturation of the condensate liquid is lower than the residual saturation, therefore, the mobility and relative permeability of condensate liquid are low, and the condensate is immobile [2,3].

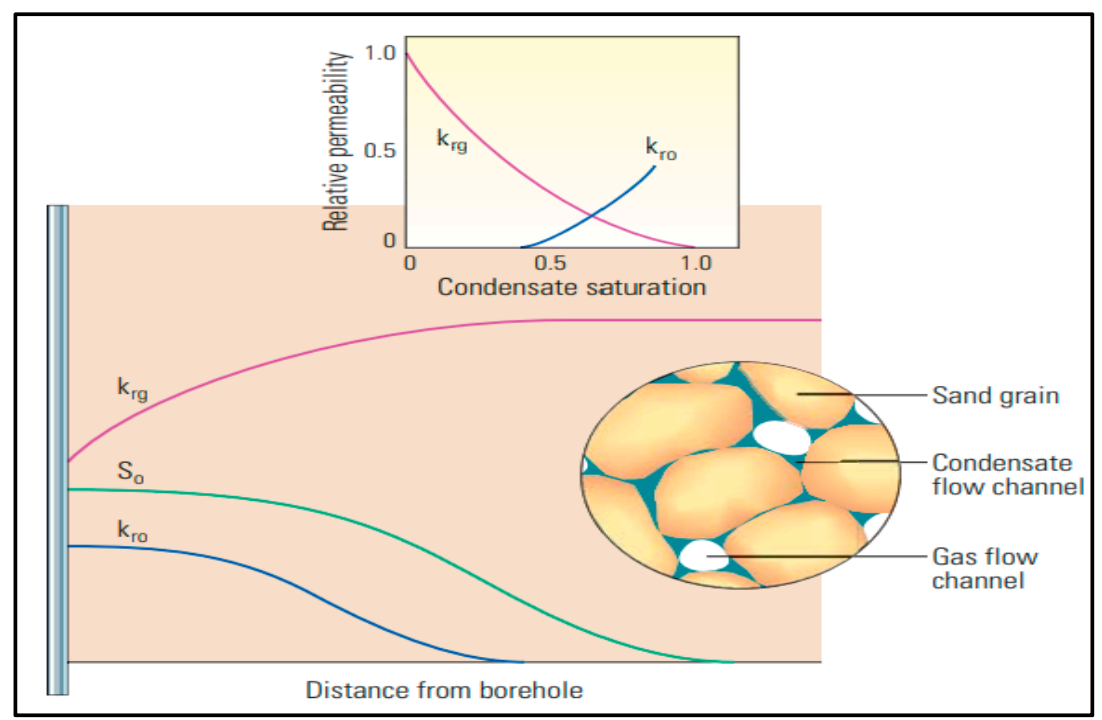

Figure 1. Condensate blockage schematic with reflection to relative permeability curves [4].

Several treatments are reported to recover the condensate liquid and enhance the deliverability of gas reservoirs [5]. Well treatments such as chemical injection or hydraulic fracturing operations are extensively applied to remove the accumulated condensate and improve the reservoir deliverability $[6,7]$. The ultimate objective of these treatments is to create more favorable flow conditions by either reducing the condensate viscosity or decreasing the drawdown pressure that is required to flow the hydrocarbon into wellbore.

Solvents are injected into reservoirs to reduce the condensate viscosity by dissolving some of the condensate elements back into the gaseous state [8]. Methanol is the most common solvent used in field applications. Methanol displacement of liquid accumulations is attributed to the multi-contact-miscible technique [9]. Considerable enhancement in the relative permeability to gas are reported by using methanol injection for both sandstone and carbonate reservoirs [10,11]. The problem with solvent injection is that, the production enhancement will fade away after few months ( 3 to 6 months), which is attributed to the depletion of solvents during well production, leading to decrease their effects significantly. Therefore, solvents injection is considered a temporary method for condensate removal, and the treatment is repeated frequently based on the reservoir situation [8].

Hydraulic fracturing is applied to generate conductive paths between the reservoir and the treated well. The generated fractures reduce the pressure drop significantly, which leads to delay of the condensate accumulation. In addition, these conductive paths contribute to the condensate production and reduces its saturation [12]. In some cases, the fracture treatment resulted in enhancing the total gas production from tight carbonate reservoirs by three folds [13]. The performance of fracturing treatment is depending on several factors including; formation properties, hydrocarbon composition, and injected fluids. Hydraulic fracturing provides an effective tool in delaying the condensate accumulation around the wellbore. However, hydraulic fracturing is considered an expensive treatment. The operational cost varies between $\$ 300,000$ and $\$ 800,000$ for treating the vertical wells, and it could reach to $\$ 2$ million for the horizontal wells. Moreover, fracturing operations might result in several environmental concerns such as contamination of groundwater or small earthquakes [14]. 
Gas injection into hydrocarbon reservoirs helps sustain the pressure above dew point [15-17], and therefore, prevent the generation of condensate banking. Carbon dioxide injection is a common and very effective solution for condensate removal in tight gas reservoirs [18]. Zhengyuan et al. [19] studied the impact of carbon dioxide injection on removing the condensate banking. Several experiments were conducted including coreflooding tests and pressure-volume-temperature (PVT) measurements. They concluded that, injection of carbon dioxide is recommended over water flooding for removing the condensate damage and improving the gas deliverability. The problem of $\mathrm{CO}_{2}$ injection is that it is a temporary solution and has to be repeated frequently in the field in addition to the supply limitations of $\mathrm{CO}_{2}$ in some areas [4]. In addition, the infrastructure required at the surface to handle $\mathrm{CO}_{2}$ injection makes it expensive to apply $\mathrm{CO}_{2}$ injection for condensate removal.

The current methods of condensate removal showed several limitations, such as temporary removal of condensate banking or limited improvements in the gas productivity as well as the expensive operations of some condensate treatments. Therefore, the industry is looking for new and permanent techniques to mitigate the condensate damage. One of the promising techniques is the in situ generation of heat and pressure at reservoir conditions. This treatment is conducted by injecting chemical solutions to react at downhole conditions and generate heat and pressure. The induced heat and pressure could be designed in such a way to remove the condensate bank by vaporizing the liquid and converting it to the gaseous phase. In addition, the generated pressure could be maximized to create micro-factures, which will reduce the capillary forces and improves the gas relative permeability.

This paper introduces a new method for removing the condensate banking from tight formations, by utilizing chemical injection. Tight sandstone samples were flooded with two thermochemicals to remove the condensate and improve the flow conditions. The used chemicals are able to generate in situ, nitrogen, steam, heat, and pressure at reservoir conditions. The two chemicals are stable at surface conditions, and they start the reaction at downhole conditions. Reaction products are produced only when the reaction is triggered. The thermochemical reaction can be triggered by either the reservoir temperature or a chemical activator. In this work, an activator was utilized to trigger the reaction, which led to shortening the time of reaction. The generated temperature and pressure were able to remove the condensate and reduce its viscosity significantly. In addition, tiny fractures were observed in all core samples after the treatment operations. The generated fractures showed significant improvements in the gas relative permeability and capillary forces.

\section{Experimental Approach}

\subsection{Materials}

Core samples were prepared for coreflooding experiments to evaluate the performance of thermochemical treatment on removing the condensate liquid. Scioto sandstone samples were used; the mineralogical composition was determined. The samples showed a high percentage of Quartz $(70 \%)$, a medium quantity of Illite (18\%), and traces of Feldspar (2\%) and Kaolinite (1\%). In addition, Chlorite and Plagioclase minerals were detected with weight percentages of $4 \%$ and $5 \%$, respectively. The core samples were characterized by measuring the porosity and absolute permeability [20]. The properties of core samples used in flooding tests is listed in Table 1 . The average permeability and porosity are $0.9 \mathrm{mD}$ and $16.5 \%$, respectively. Actual condensate liquid was utilized in the flooding experiments, the condensate has an American Petroleum Institute (API) gravity of $48^{\circ}$ and viscosity of $1.8 \mathrm{cP}$ at the surface condition. Two thermochemical fluids (ammonium chloride and sodium nitrite) were injected at a ratio of one to one molar ratio, and acetic acid was used for triggering the reaction to shorten the time required for thermochemical treatment. The following equation represents the thermochemical reaction:

$$
\mathrm{NH}_{4} \mathrm{Cl}+\mathrm{NaNO}_{2} \rightarrow \mathrm{NaCl}+2 \mathrm{H}_{2} \mathrm{O}+\mathrm{N}_{2} \text { (gas) }+\Delta \mathrm{H} \text { (heat) }
$$


Table 1. Core samples properties.

\begin{tabular}{ccccccc}
\hline $\begin{array}{c}\text { Sample } \\
\text { ID }\end{array}$ & $\begin{array}{c}\text { Diameter } \\
(\mathbf{c m})\end{array}$ & $\begin{array}{c}\text { Length } \\
(\mathbf{c m})\end{array}$ & $\begin{array}{c}\text { Bulk Volume } \\
(\mathbf{m L})\end{array}$ & $\begin{array}{c}\text { Pore Volume } \\
(\mathbf{m L})\end{array}$ & $\begin{array}{c}\text { Porosity } \\
(\mathbf{\%})\end{array}$ & $\begin{array}{c}\text { Absolute Permeability } \\
(\mathbf{m D})\end{array}$ \\
\hline $\mathbf{1}$ & $\mathbf{3 . 8 1}$ & $\mathbf{7 . 3 4}$ & $\mathbf{8 3 . 7 2}$ & $\mathbf{1 4 . 2 9}$ & $\mathbf{1 7 . 0 7}$ & 0.898 \\
$\mathbf{2}$ & 3.81 & 2.54 & 28.95 & 4.61 & 15.93 & 0.900 \\
\hline
\end{tabular}

\subsection{Coreflooding Setup}

Coreflooding setup was built to run the thermochemical flooding experiments. The system consists of a core holder to accommodate the core sample; high pressure pump and three transfer cells for injecting the oil water and chemicals; pressure gauges to monitor the confining pressures; back pressure regulator to set the pore pressure; and a fraction collector to collect the produced effluent. A schematic of the used coreflooding setup is illustrated in Figure 2. Overburden pressure of $1000 \mathrm{psi}$ and back pressure of $400 \mathrm{psi}$ and injection rate of $0.5 \mathrm{cc} / \mathrm{min}$ were applied. The core samples were saturated with condensate liquid using saturation system under high pressure. A vacuum was applied to remove the gases from the core rocks, then, the condensate liquid was injected into the samples using injection pump. The samples were aged/kept in the condensate liquid, at high pressure conditions overnight to ensure the cores were $100 \%$ saturated with condensate. Two injection methods were used in the flooding experiment; continuous flooding and the huff and puff technique. The injection rate was maintained at $0.5 \mathrm{~cm}^{3} / \mathrm{min}$ for all flooding experiments. The injected volume of acetic acid (activator) is two $\mathrm{ml}$ for each $5 \mathrm{~mL}$ of $\mathrm{NH}_{4} \mathrm{Cl}$ and $\mathrm{NaNO}_{2}$ (thermochemical reagent). The activator was injected at a flow rate of $0.5 \mathrm{~cm}^{3} / \mathrm{min}$, and it was injected every $10 \mathrm{~min}$ for triggering the reaction. Based on the experimental study it was found out that $2 \mathrm{~mL}$ of acetic acid was enough for triggering the chemical reaction. The produced effluents from all flood tests were collected, and the inlet and outlet pressures were recorded.

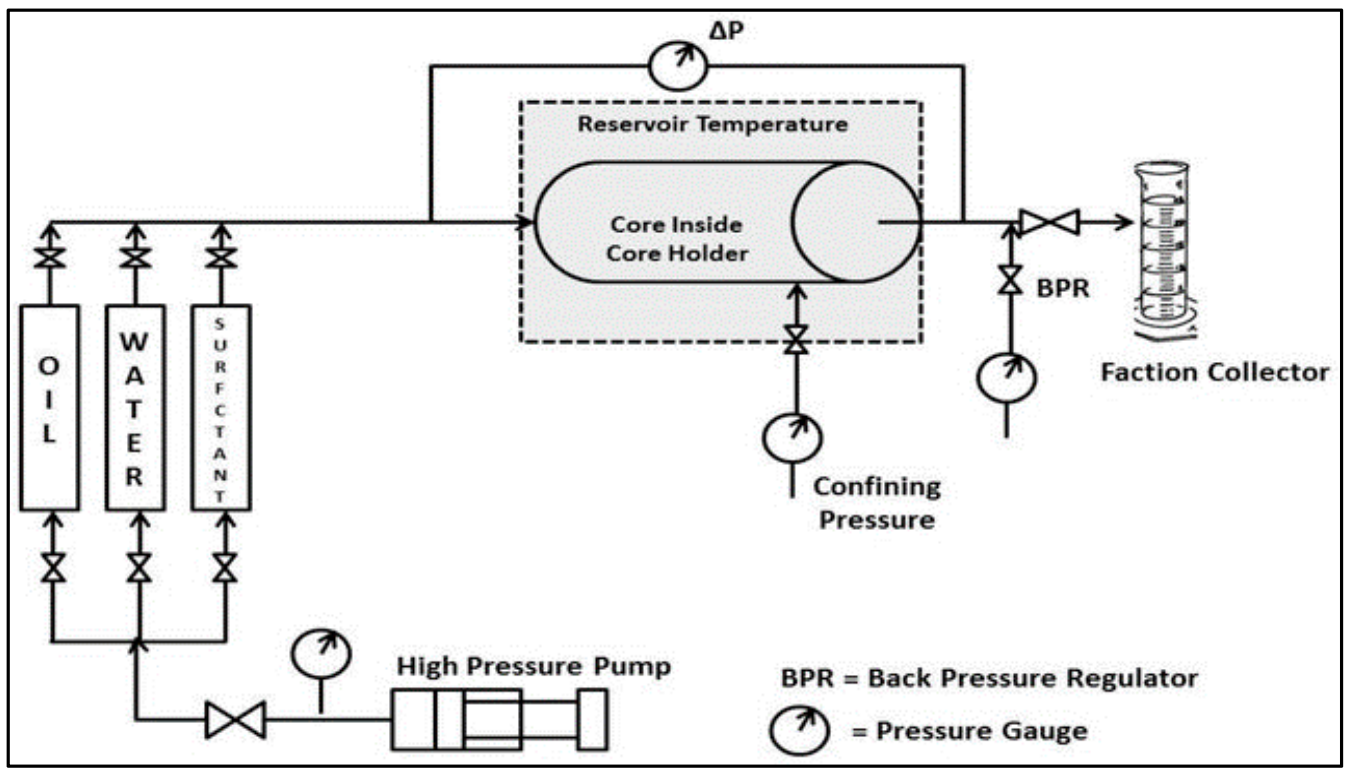

Figure 2. Coreflooding Setup.

\section{Results and Discussion}

\subsection{Condensate Removal}

Coreflooding tests were carried out to study the effectiveness of thermochemical treatment in recovering the condensate liquid. Figure 3 shows the profiles of condensate recovery and pressures at the inlet and outlet. They recovered $63 \%$ of the original condensate by injecting 2.1 pore volume of thermochemical fluids. The inlet pressure increased significantly due to the thermochemical reaction, 
a pressure of 2300 psi was achieved at the core inlet. The back pressure regulator was utilized to maintain the outlet pressure at $400 \mathrm{psi}$. The condensate recovery could be attributed to several mechanisms such as viscosity reduction, immiscible displacement, and alteration of rock properties. The generated pressure due to chemicals reaction reached $2300 \mathrm{psi}$, which leads to significant changes in the condensate behavior. The effect of thermochemical treatment on the properties of condensate liquid was investigated using the WinProp suit from the computer modeling group (CMG) software (c). The two-phase envelop was generated utilizing the condensate composition. Thereafter, the alterations in condensate phase due to thermochemical treatment was determined. Figure 4 shows the generation of condensate liquid during gas production, and the phase change from condensate liquid to gas due to thermochemical treatment. Based on the two-phase diagram, the condensate liquid could be turned into a gas phase by pressurizing the condensate region, which results in significant reduction in the hydrocarbon viscosity and solubility of the liquid condensate in the gaseous phase.

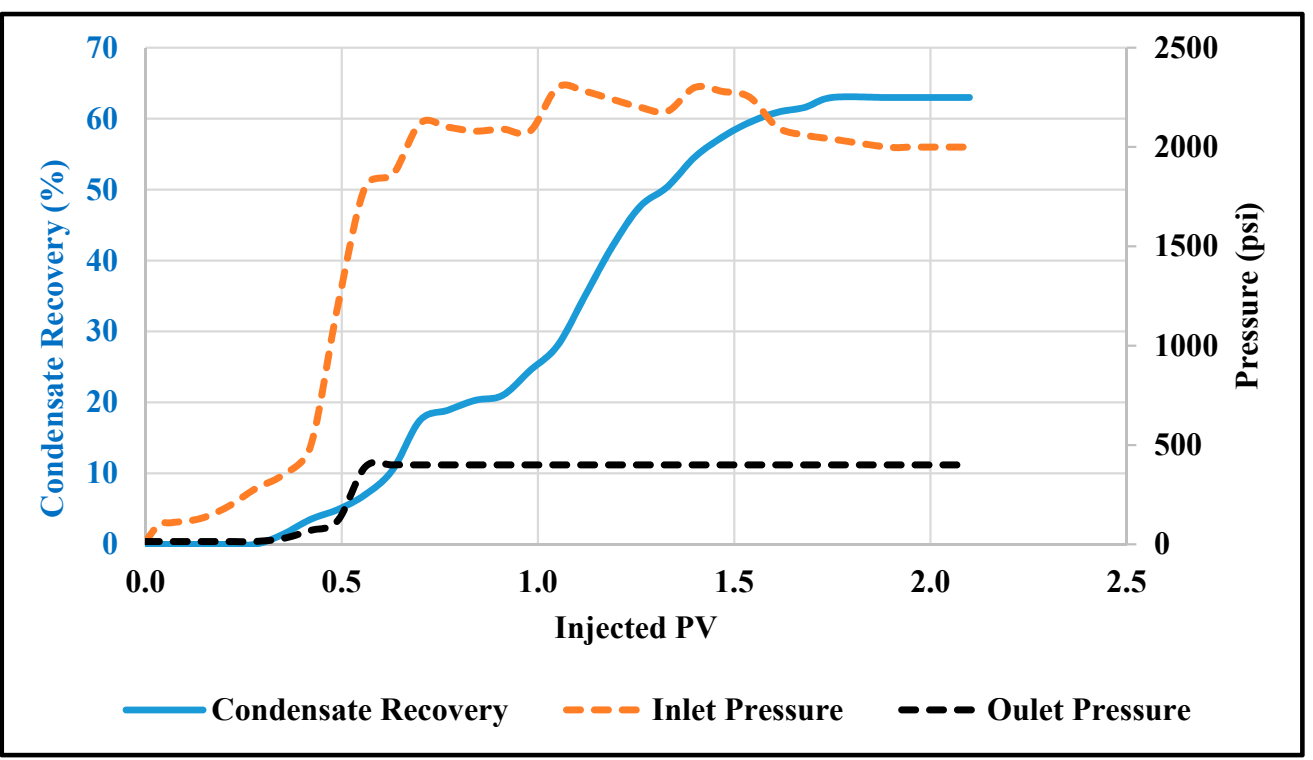

Figure 3. Profiles of condensate recovery, inlet, and outlet pressures for continuous injection of thermochemical fluids.

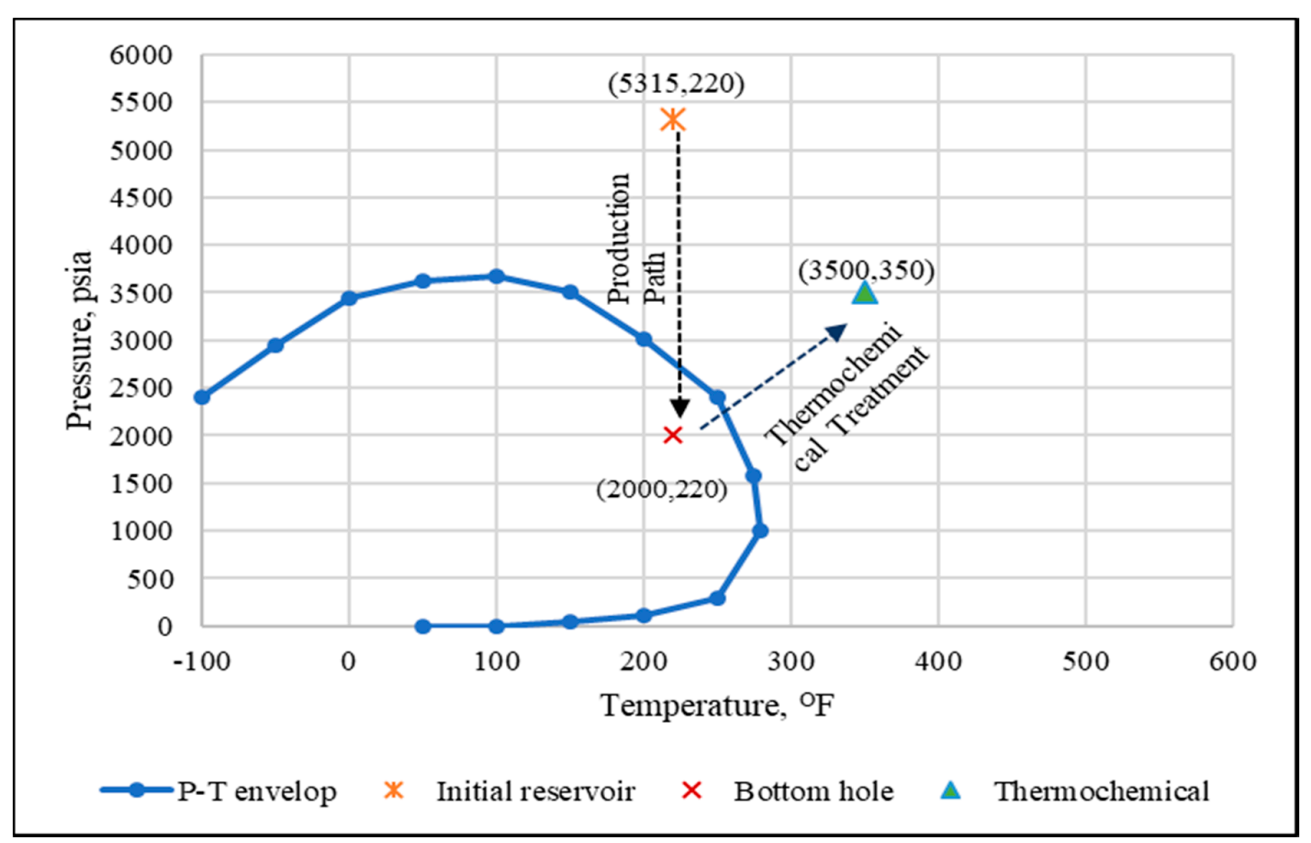

Figure 4. Alterations of condensate behavior due to thermochemical treatment, at reservoir conditions. 
In addition, the pressure pulses alter the rock properties, especially the permeability and capillary forces. Tiny fractures were observed in all core samples after flooding operations. The generated factures would contribute in recovering the condensate liquid, by decreasing the capillary forces that hold the condensate. Those fractures were developed due to a rapid increase in the pore pressure when the thermochemical reaction was activated. As shown in Figure 3, the pressure at the core inlet (orange curve) increased dramatically from 200 psi to 2300 psi. Furthermore, the thermochemical reaction generated a significant amount of gases, such as nitrogen and steam. A considerable volume of gases was observed in the produced effluent. The generated gases contributed in the condensate recovery by improving the condensate mobility. The flooding is immiscible displacement, because the minimum miscibility pressure (MMP) of nitrogen is higher than the pore pressure. The maximum pore pressure was $2300 \mathrm{psi}$, while the MMP for nitrogen was $5800 \mathrm{psi}$.

The huff and puff technique [18] was applied to remove the condensate banking. The thermochemical fluids were injected into the core samples, then the rock samples were soaked for 40 min to allow the chemical reaction to take place. After that, the condensate was produced from the core sample for $25 \mathrm{~min}$. The primary mechanism for producing the condensate is the in situ generated pressure inside the core sample. The soaking and production periods were determined based on pressure and recovery stabilization. Figure 5 illustrates the profiles of condensate recovery and pressures at the core inlet and outlet. Four cycles of huff and puff were applied; $56 \%$ of the condensate was recovered in the first cycle, recovery of $5 \%$ was obtained in the second cycle, while the third and fourth cycles resulted in $1.8 \%$ and $1.5 \%$, respectively. During the soaking periods, the pore pressure increased significantly due to thermochemical reaction, and a pressure of 1900 psi was observed. The generated pressure showed significant impact on the core properties; micro-fractures were observed in the sample after the flooding operation. The huff and puff treatment resulted in $35 \%$ of remaining condensate saturation, which could be considered as irreducible saturation and at which the condensate liquid is immobile. In addition, the huff and puff operation indicates that two cycles of thermochemical injection and production is sufficient for removing the condensate banking, since the third and fourth cycles showed limited improvement in the condensate removal (less than $2 \%$ was recovered).

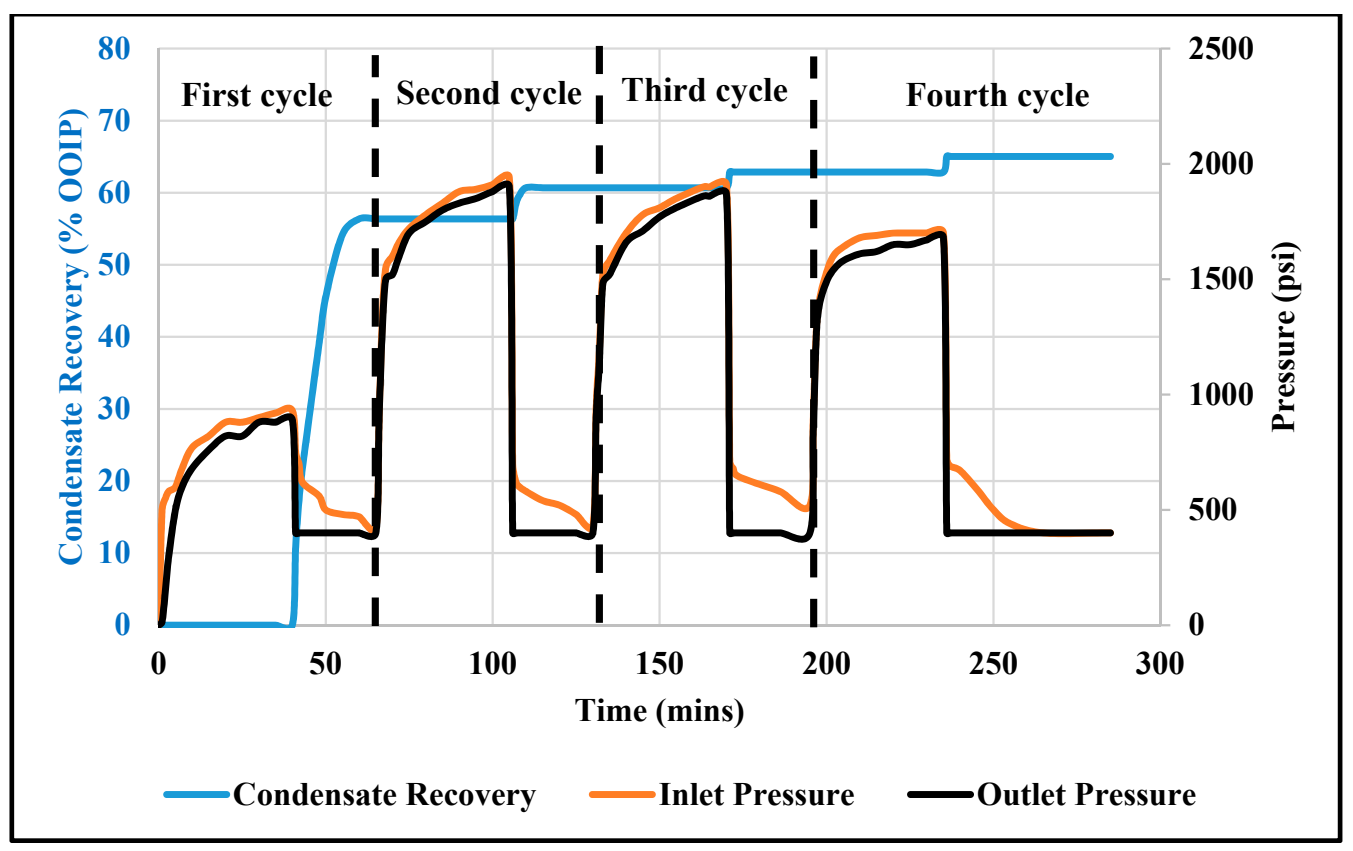

Figure 5. Profiles of condensate recovery, inlet, and outlet pressures for the huff and puff mode.

Comparing the two flooding modes, the continuous injection of thermochemical fluids and the huff and puff operations, showed that huff and puff is preferred for condensate treatment. Figure 6 shows the condensate recovery using continuous injection of thermochemical (blue) and the huff 
and puff mode (orange). Both techniques provided an equivalent condensate recovery, $62.98 \%$ and $65.03 \%$ were obtained from the continuous and huff and puff modes, respectively. However, less volume of chemicals was used during the huff and puff technique, which will reduce the operational cost. Therefore, the huff and puff mode is more effective than continuous injection in removing the condensate banking. The soaking periods during the huff and puff operations provide more time for the chemicals to react, which improves the performance of thermochemical treatment. Further investigation of the huff and puff process is required to optimize the duration of each cycle and the amount of injected chemicals.

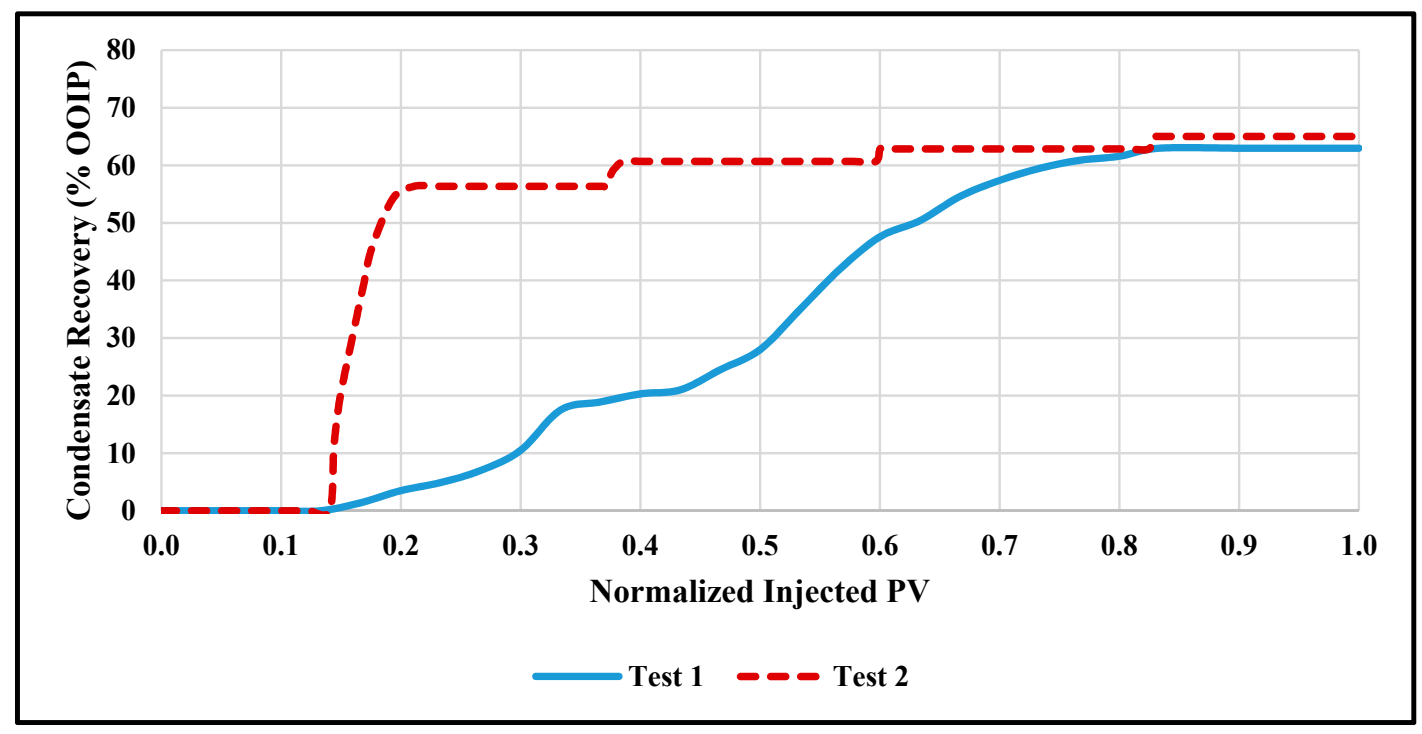

Figure 6. Condensate recovery using continuous injection of thermochemical (Test 1) and huff and puff mode (Test 2).

\subsection{Generation of Micro-Fractures}

Injection of thermochemical fluids into tight samples resulted in generating micro-factures due to the pressure pulses. Tiny fractures were observed in all core samples after the flooding operations, with more fractures were generated close to the core inlet, as shown in Figure 7. To confirm the generation of micro-fractures, NMR (Nuclear Magnetic Resonance) was conducted on the samples after the coreflooding tests. Figure 8 shows the profiles of incremental and cumulative porosity for the samples before and after thermochemical injection. Before the treatment, single peak was observed which indicate a uni-porosity model. However, after the chemical treatment, two peaks were observed, which reveals that the induced fractures led to change the pore size distribution from the uni-porosity model to the double-porosity model. Therefore, it can be concluded that new pores were generated inside the cores after the flooding. However, the treatment with thermochemical solutions showed no impact on the cumulative porosity. Results of NMR measurements confirm the generation of micro-fractures due to the thermochemical treatment. 


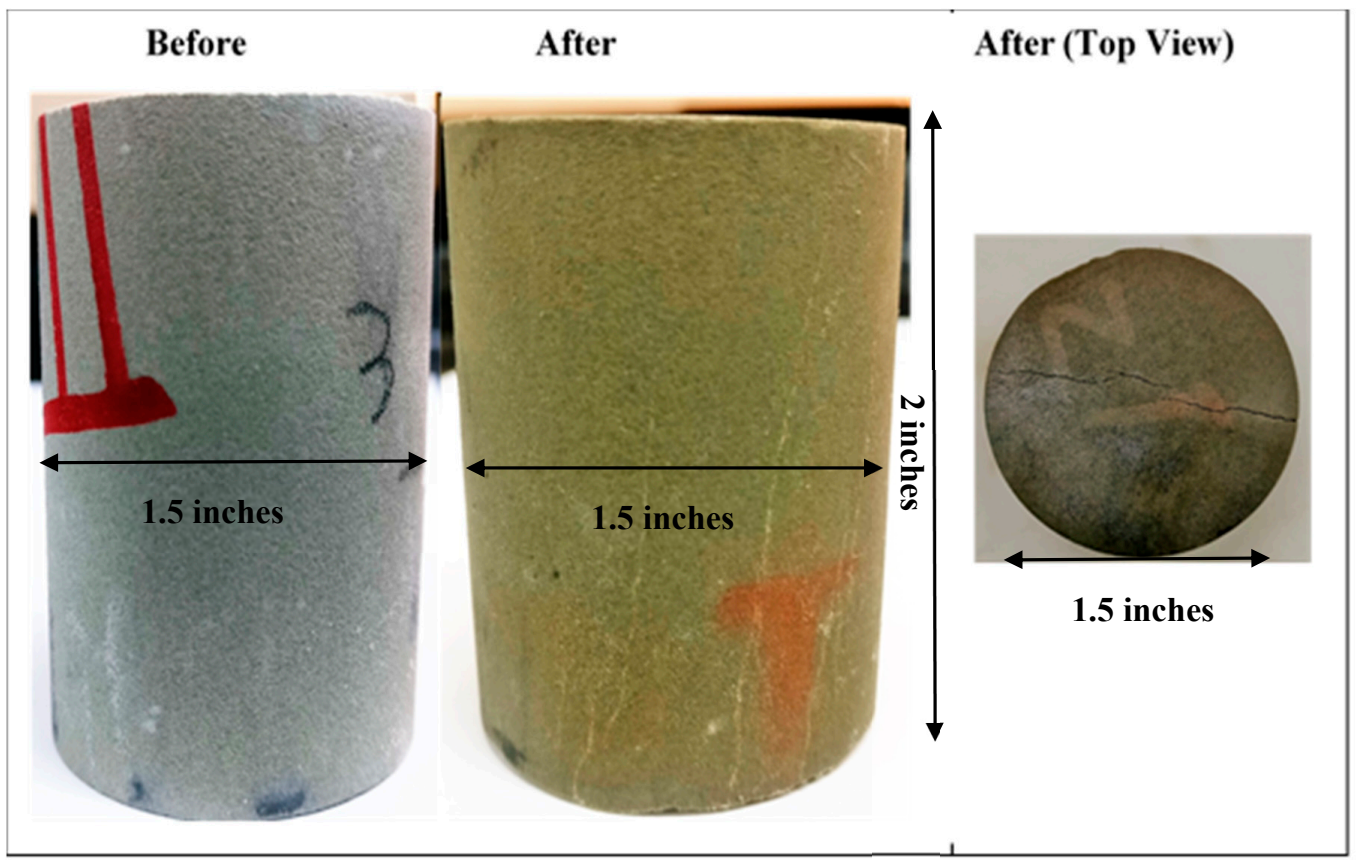

Figure 7. Images for the core samples before and after the thermochemical injection.

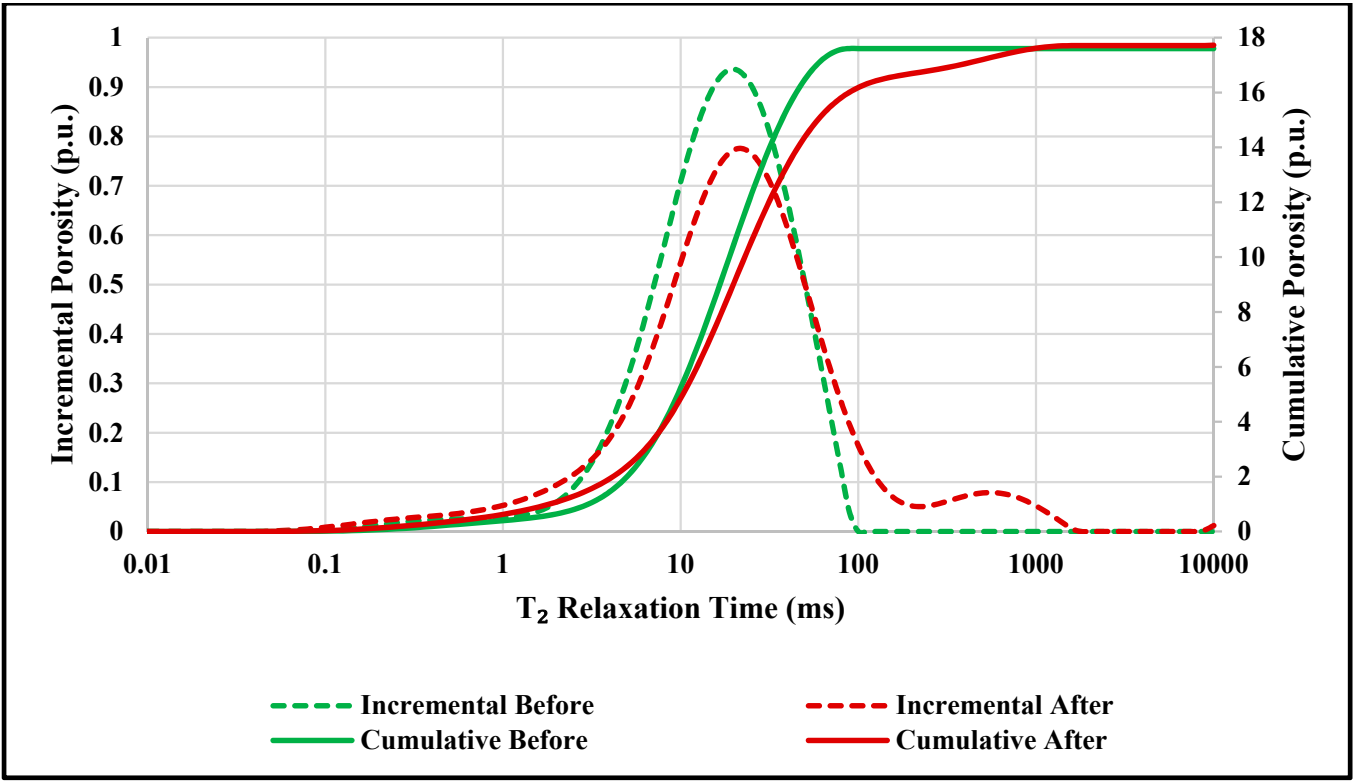

Figure 8. Incremental and cumulative porosity distribution for the sample before (green) and after (red) thermochemical injection.

\subsection{Gas Relative Permeability}

Condensate banking reduces the gas relative permeability significantly, with a reduction of up to $80 \%$ being reported [20]. Injecting thermochemical fluids will lead to an improvement in the effective permeability to gas by reducing the condensate saturation and developing conductive paths for gas to flow. The improvement of gas relative permeability due to thermochemical treatment could be estimated using mathematical models. Several models are reported to predict the relative permeability; such as Corey, Brooks and Corey and Honarpour et al. [21-25]. Equations (1)-(3) were used to determine the relative permeability curves before and after chemical treatment [23]. 


$$
\begin{gathered}
\mathrm{k}_{\text {row }}=0.76067\left[\frac{\left(\frac{\mathrm{S}_{\mathrm{o}}}{1-\mathrm{S}_{\text {iw }}}\right)-\mathrm{S}_{\text {or }}}{1-\mathrm{S}_{\text {orw }}}\right]^{1.8}\left[\frac{\mathrm{S}_{\mathrm{o}}-\mathrm{S}_{\text {orw }}}{1-\mathrm{S}_{\text {orw }}-\mathrm{S}_{\text {orw }}}\right]^{2}+2.6318 \varnothing\left(1-\mathrm{S}_{\text {orw }}\right)\left(\mathrm{S}_{\mathrm{o}}-\mathrm{S}_{\text {orw }}\right) \\
\mathrm{k}_{\text {rog }}=0.98372\left[\frac{\mathrm{S}_{\mathrm{o}}}{1-\mathrm{S}_{\mathrm{iw}}}\right]^{4}\left[\frac{\mathrm{S}_{\mathrm{o}}-\mathrm{S}_{\text {org }}}{1-\mathrm{S}_{\text {iw }}-\mathrm{S}_{\text {org }}}\right]^{2} \\
\mathrm{k}_{\mathrm{rg}}=1.1072\left[\frac{\mathrm{S}_{\mathrm{g}}-\mathrm{S}_{\mathrm{gc}}}{1-\mathrm{S}_{\mathrm{iw}}}\right]^{2} \mathrm{~K}_{\text {rgo }}+2.7794 \mathrm{~S}_{\text {org }}\left[\frac{\mathrm{S}_{\mathrm{g}}-\mathrm{S}_{\mathrm{gc}}}{1-\mathrm{S}_{\text {iw }}}\right] \mathrm{K}_{\text {rgro }}
\end{gathered}
$$

The profiles of relative permeability for gas and condensate were calculated before and after the treatment, as shown in Figure 9. Based on the coreflooding experiments, the condensate saturation was reduced by $65 \%$, consequently, the relative permeability for the condensate and gas will be affected. In addition, the irreducible water saturation (Swi) was reduced by $50 \%$ due to the reduction in capillary forces, which will influence the Krg as shown in Equation (3). Considerable reduction in the relative permeability for gas was observed due to the condensate banking. A gas relative permeability of less than 0.05 was obtained before the treatment. Injecting thermochemical fluids results in enhancing the relative permeability for gas. The gas relative permeability was improved by a factor of 1.22 due to the thermochemical treatment.

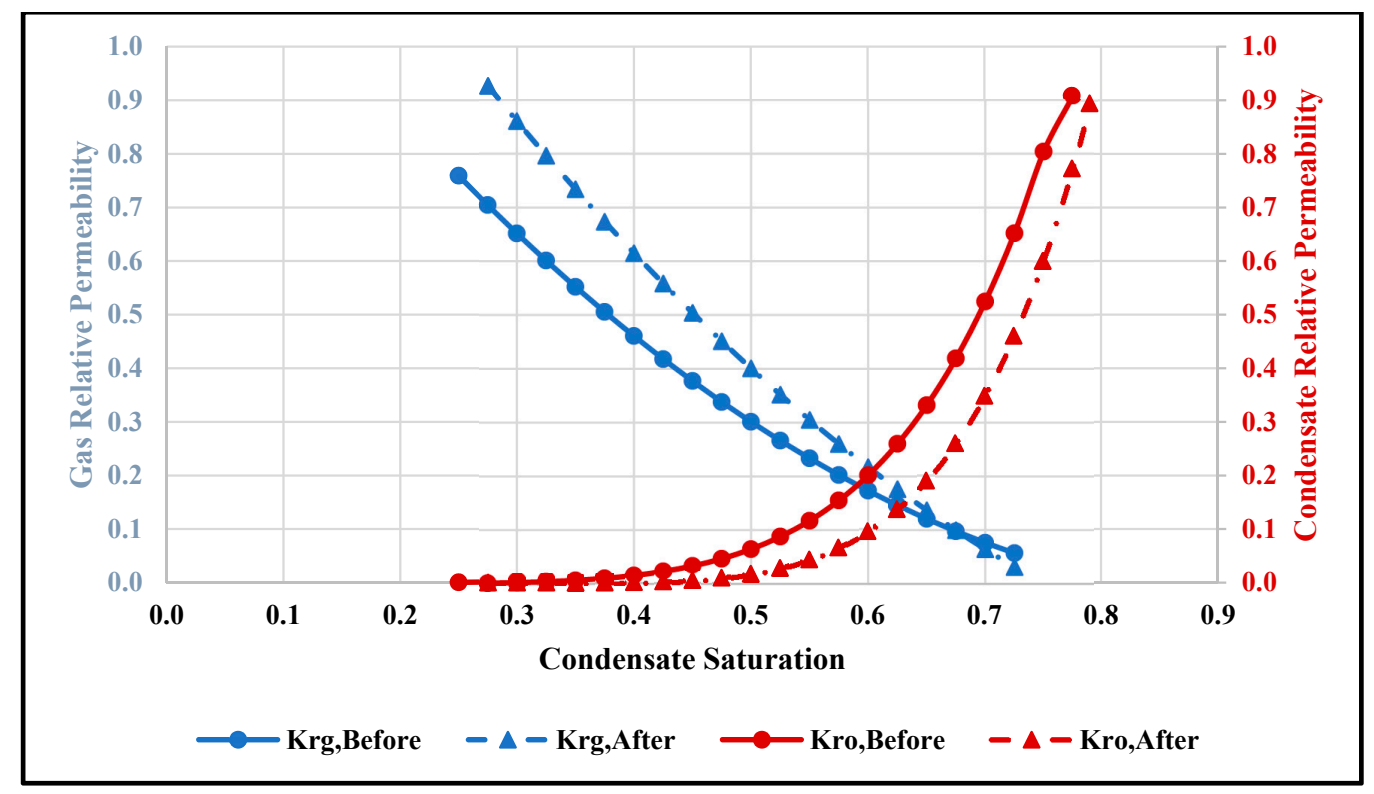

Figure 9. Relative permeability curves for gas $\left(\mathrm{K}_{\mathrm{rg}}\right)$ and condensate $\left(\mathrm{K}_{\mathrm{ro}}\right)$.

\subsection{Enhancement of Gas Mobility}

The fluid mobility plays a significant role in the well productivity, usually higher mobility means better flow conditions. The fluid mobility is determined based on the ratio of effective permeability to fluid viscosity. The fluid mobility can be maximized by increasing the effective permeability or reducing the fluid viscosity. Injecting thermochemical fluids into gas reservoirs leads to an enhancement of the gas mobility by reducing the hydrocarbon viscosity and enhancing the gas effective permeability. Thermochemical treatment increases the reservoir pressure and temperature, around the borehole, beyond the dew point curve as shown in Figure 4.

The condensate liquid will be converted into the gaseous phase due to the in situ generation of heat and pressure. Converting the liquid condensate into the gas phase will result in reducing the fluid viscosity significantly. The viscosities of gas and condensate are 0.02 and $0.34 \mathrm{cP}$, respectively. Therefore, the hydrocarbon viscosity can be reduced 17 times using thermochemical treatment. Micro-fractures will be generated during thermochemical treatment due to the pressure pluses. The developed fractures 
will result in reducing the capillary forces that hold the condensate, then, more condensate will be recovered. The reduction in capillary forces can be predicted using Equation (4) [22];

$$
\begin{gathered}
\mathrm{P}_{\mathrm{c}}=\mathrm{P}_{\mathrm{d}} \mathrm{S}_{\mathrm{e}}^{-\frac{1}{\lambda}} \\
\mathrm{S}_{\mathrm{e}}=\frac{\mathrm{S}_{\mathrm{con}}-\mathrm{S}_{\mathrm{conr}}}{1-\mathrm{S}_{\mathrm{conr}}}
\end{gathered}
$$

where $P_{d}$ is the displacement or threshold pressure, Se is the effective fluid saturation and $\lambda$ is the pore-size-distribution parameter, for sandstone lambda is 4.17 . The improvement in capillary conditions due to thermochemical treatment was determined by utilizing the coreflooding results and capillary pressure model. Figure 10 shows the reduction in capillary pressures due to thermochemical treatment. The capillary forces were reduced by $51 \%$ using the thermochemical flooding, the values of capillary pressure before and after treatment were 65.5 and 32.4 psi, respectively. Combining the improvement in capillary forces with the reduction of fluid viscosity, the ultimate enhancement in hydrocarbon mobility will reach $94 \%$.

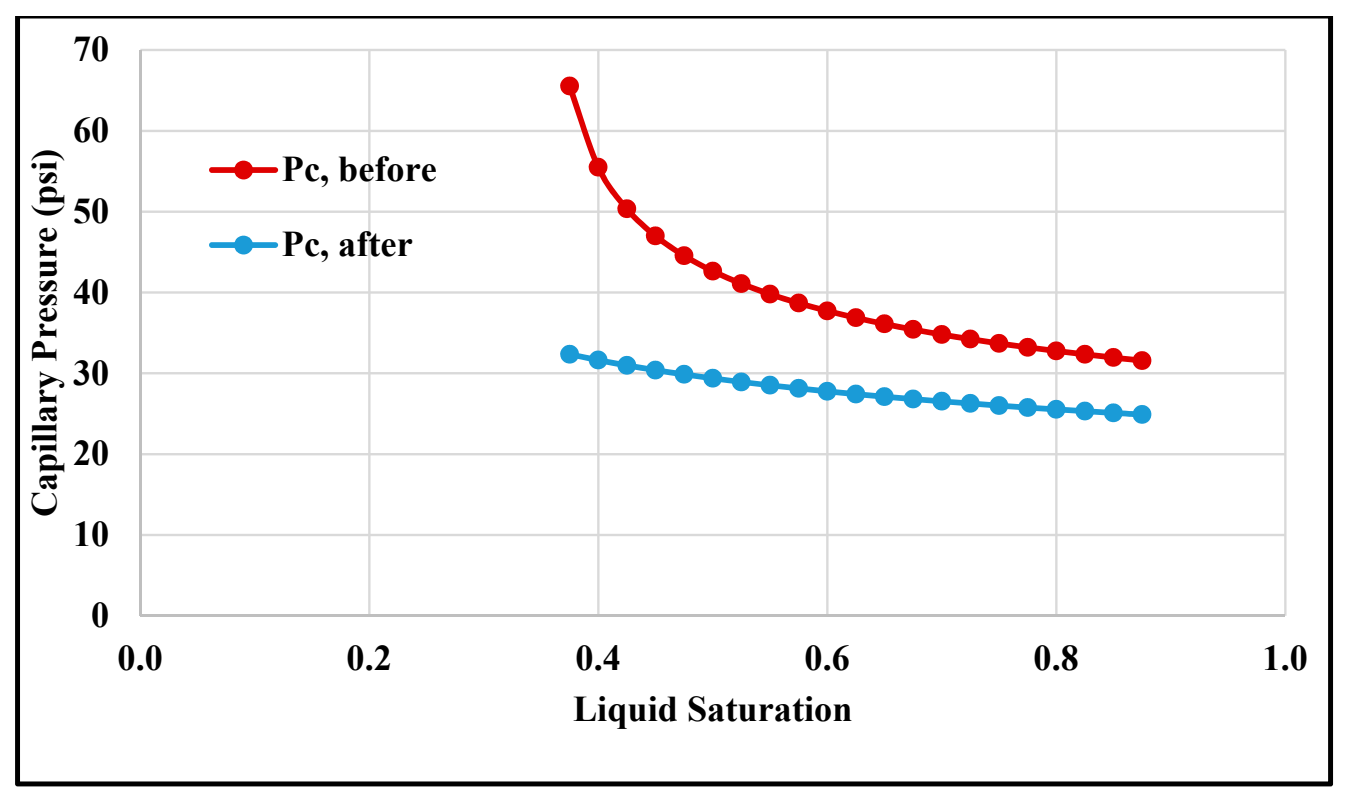

Figure 10. Capillary pressure curves before and after thermochemical treatment.

\section{Conclusions}

A new technique for removing the condensate banking by using thermochemical fluids is presented. The influence of thermochemical treatment on reducing the condensate saturation and improving the gas mobility were investigated. The following conclusions could be drawn from this work;

- Thermochemical treatment removes more than $65 \%$ of the condensate banking, utilizing viscosity reduction and immiscible mechanisms.

- The huff and Puff mode showed better performance than continuous chemical injection in mitigating the condensate damage and minimizing the injected chemicals.

- Removing the condensate banking improves the gas effective permeability. The relative permeability to gas was improved by a factor of 1.22 using the thermochemical treatment.

- The pressure pulse generated due to the reaction and the high temperature created micro-fractures in the tight sandstone. Tiny fractures were observed in all samples after the chemical treatment.

- Injecting thermochemical fluids improved the gas mobility by reducing the condensate viscosity and enhancing the gas effective permeability. The hydrocarbon viscosity was reduced 17 times using thermochemical treatment. 
- The reduction in capillary pressure due to thermochemical treatment was determined, and a reduction of $51 \%$ in the capillary forces was achieved. The values of capillary pressure before and after treatment were 65.5 and 32.4 psi, respectively.

- Combining the improvement in capillary forces with the reduction of fluid viscosity revealed that the ultimate enhancement in hydrocarbon mobility would reach $94 \%$.

Author Contributions: Conceptualization, A.M.H., M.A.M., A.R.A.-N., M.B. and S.E.; Data curation, A.M.H.; Formal analysis, A.M.H., M.A.M. and A.A.A.-M.; Funding acquisition, A.R.A.-N. and M.A.B.; Investigation, A.M.H., M.A.M., A.A.A.-M.; Resources, A.R.A.-N. and M.A.B.; Supervision, M.A.M. and A.A.A.-M.; Validation, M.A.M., A.A.A.-M.; Writing—original draft, A.M.H.; Writing—review \& editing, M.A.M. and A.A.A.-M.

Funding: This research was funded by [Saudi Aramco] grant number [CIPR2317]" and "The APC was funded by [the college of Petroleum and Geoscience at King Fahd University of Petroleum \& Minerals]".

Acknowledgments: Authors would like to acknowledge the college of Petroleum and Geoscience at King Fahd University of Petroleum \& Minerals and Saudi Aramco for the support and permission to publish this work. Saudi Aramco is also acknowledged for funding this research under project number CIPR2317. Authors are grateful to Syed Rizwanullah for conducting the CT-scan and NMR measurements. We also thank Abdulrauf Adebayo and Jack Dvorkin for approval to access the NMR and CT equipment, respectively, at the Center for Integrative Petroleum Research (CIPR)-CPG, KFUPM.

Conflicts of Interest: The authors declare no conflict of interest.

\section{Nomenclature}

$\begin{array}{ll}\mathrm{k}_{\mathrm{r}} & \text { relative permeability } \\ \mathrm{P}_{\mathrm{c}} & \text { capillary pressure, psi } \\ \mathrm{S}_{\mathrm{con}} & \text { condensate saturation } \\ \mathrm{S}_{\mathrm{conr}} & \text { residual condensate saturation } \\ \mathrm{S}_{\mathrm{gc}} & \text { critical gas saturation } \\ \mathrm{S}_{\mathrm{gr}} & \text { residual gas saturation } \\ \mathrm{S}_{\mathrm{wi}} & \text { irreducible water saturation } \\ \mu & \text { viscosity, cP } \\ \phi & \text { porosity }\end{array}$

\section{References}

1. Chai, J.; Shi, H.; Zhou, X.; Wang, S. The Price Elasticity of Natural Gas Demand in China: A Meta-Regression Analysis. Energies 2018, 11, 3255. [CrossRef]

2. Fevang, $\Phi . ;$ Whitson, C.H. Modeling Gas-Condensate Well Deliverability. SPE Reserv. Eng. 1996, 11, $221-230$. [CrossRef]

3. Marokane, D.; Logmo-Ngog, A.B.; Sarkar, R. Applicability of timely gas injection in gas condensate fields to improve well productivity. In Proceedings of the SPE/DOE Improved Oil Recovery Symposium, SPE75147, Tulsa, OK, USA, 13-17 April 2002. [CrossRef]

4. Sayed, M.A.; Al-Muntasheri, G.A. Mitigation of the effects of condensate banking: A critical review. SPE Prod. Oper. 2016, 31, 85-102. [CrossRef]

5. Alvarado, V.; Manrique, E. Enhanced oil recovery: An update review. Energies 2010, 3, 1529-1575. [CrossRef]

6. Al-Anazi, H.; Xiao, J.J.; Al-Eidan Ahmed, A.; Buhidma Ismail, M.; Ahmed Mahbub, S.; Al-Faifi Mohammad, G.; Assiri Wisam, J. Gas Productivity Enhancement by Wettability Alteration of Gas-Condensate Reservoirs. In Proceedings of the European Formation Damage Conference, SPE107493, Scheveningen, The Netherlands, 30 May-1 June 2007. [CrossRef]

7. Wang, D.; Shi, F.; Yu, B.; Sun, D.; Li, X.; Han, D.; Tan, Y. A Numerical Study on the Diversion Mechanisms of Fracture Networks in Tight Reservoirs with Frictional Natural Fractures. Energies 2018, 11, 3035. [CrossRef]

8. Du, L.; Walker, J.G.; Pope, G.A.; Sharma, M.M.; Wang, P. Use of solvents to improve the productivity of gas condensate wells. In Proceedings of the SPE Annual Technical Conference and Exhibition, SPE62935, Dallas, TX, USA, 1-4 October 2000. [CrossRef] 
9. Al-Anazi, H.; Al-Otaibi, M.; Al-Faifi, M.; Hilab, V. Enhancement of Gas Productivity Using Alcoholic Acids: Laboratory and Field Studies. In Proceedings of the SPE Annual Technical Conference and Exhibition, SPE102383, San Antonio, TX, USA, 24-27 September 2006. [CrossRef]

10. Al-Anazi, H.A.; Pope, G.A.; Sharma, M.M.; Metcalfe, R.S. Laboratory measurements of condensate blocking and treatment for both low and high permeability rocks. In Proceedings of the SPE Annual Technical Conference and Exhibition, SPE77546, San Antonio, TX, USA, 29 September-2 October 2002. [CrossRef]

11. Asgari, A.; Dianatirad, M.; Ranjbaran, M.; Sadeghi, A.R.; Rahimpour, M.R. Methanol treatment in gas condensate reservoirs: A modeling and experimental study. Chem. Eng. Res. Des. 2014, 92, 876-890. [CrossRef]

12. Khan, M.N.; Siddiqui, F.I.; Mansur, S. Hydraulic Fracturing in Gas Condensate Reservoirs: Successes, Setbacks and Lessons Learnt. In Proceedings of the SPE/PAPG Annual Technical Conference, SPE142848, Islamabad, Pakistan, 10-11 November 2010. [CrossRef]

13. Franco, C.A.; Solares, J.R.; Asiri, K.S.; Shammari, N.; Alabbad, E.A.; Gomez, A.; Antonio, F. Optimization of Conventional Acid Jobs and the Historical Trend Leading to Multi-Stage Acid Fracturing Stimulation to Increase Gas-Condensate Productivity in Carbonate Reservoirs in Saudi Arabia. In Proceedings of the SPE Middle East Oil and Gas Show and Conference, SPE141339, Manama, Bahrain, 25-28 September 2011. [CrossRef]

14. EPA. Hydraulic Fracturing for Oil and Gas: Impacts from the Hydraulic Fracturing Water Cycle on Drinking Water Resources in the United States; Executive Summary; EPA: Washington, DC, USA, 2018.

15. Sänger, P.; Hagoort, J. Recovery of gas condensate by nitrogen injection compared with methane injection. SPEJ 1998, 3, 26-33. [CrossRef]

16. Hoier, L.; Cheng, N.; Whitson, C.H. Miscible gas injection in under saturated gas-oil systems. In Proceedings of the SPE Annual Technical Conference and Exhibition, SPE 90379, Houston, TX, USA, 26-29 September 2004. [CrossRef]

17. Zhang, Y.; Di, Y.; Shi, Y.; Hu, J. Cyclic $\mathrm{CH}_{4}$ Injection for Enhanced Oil Recovery in the Eagle Ford Shale Reservoirs. Energies 2018, 11, 3094. [CrossRef]

18. Odi, U. Analysis and Potential of $\mathrm{CO}_{2}$ Huff-n-Puff for Near Wellbore Condensate Removal and Enhanced Gas Recovery. In Proceedings of the SPE Annual Technical Conference and Exhibition, SPE160917, San Antonio, TX, USA, 8-10 October 2012. [CrossRef]

19. Su, Z.; Tang, Y.; Ruan, H.; Wang, Y.; Wei, X. Experimental and modeling study of $\mathrm{CO}_{2}$-Improved gas recovery in gas condensate reservoir. Petroleum 2017, 3, 87-95. [CrossRef]

20. Al-Anazi, H.A.; Pope, G.A.; Sharma, M.M. Laboratory measurement of condensate blocking and treatment for both low and high permeability rocks. In Proceedings of the SPE Annual Technical Conference and Exhibition, San Antonio, TX, USA, 29 September-2 October 2002.

21. Corey, A.T. The interrelation between gas and oil relative permeabilities. Prod. Mon. 1954, 19, $38-41$.

22. Brooks, R.H.; Corey, A.T. Hydraulic Properties of Porous Media; Hydrology Papers, No. 3; Colorado State University: Fort Collins, CO, USA, 1964; pp. 22-27.

23. Honarpour, M.; Koederitz, L.; Harvey, A.H. Relative Permeability of Petroleum Reservoirs; CRC Press: Boca Raton, FL, USA, 1986; pp. 16-41.

24. Henderson, G.D.; Danesh, A.; Tehrani, D.H.; Al-Shaidi, S.; Peden, J.M. Measurement and Correlation of Gas Condensate Relative Permeability by the Steady-State Method. SPE Reserv. Eval. Eng. 1998, 1. [CrossRef]

25. Ibrahim, M.N.M. Two-Phase Relative Permeability Prediction Using a Linear Regression Model. Ph.D. Thesis, University of Missouri-Rolla, Rolla, MO, USA, 1999.

(C) 2019 by the authors. Licensee MDPI, Basel, Switzerland. This article is an open access article distributed under the terms and conditions of the Creative Commons Attribution (CC BY) license (http://creativecommons.org/licenses/by/4.0/). 